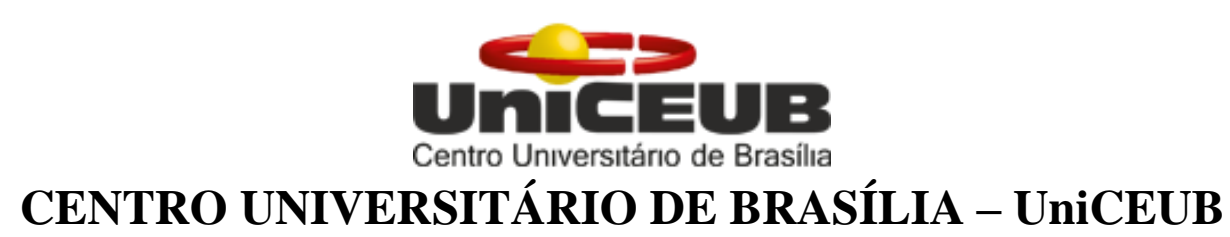

Faculdade de Tecnologia e Ciências - FATES

PROGRAMA DE INICIAÇÃO CIENTÍFICA

\author{
MATHEUS YUSEF ALI \\ BÁRBARA S BARBALHO
}

\title{
AVALIAÇÃO DA CONTAMINAÇÃO ACÚSTICA PROVOCADA PELO METRO DO DISTRITO FEDERAL (ÁGUAS CLARAS)
}

BRASÍLIA

2017

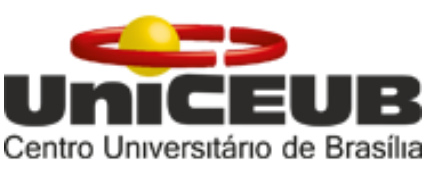




\section{AVALIAÇÃO DA CONTAMINAÇÃO ACÚSTICA PROVOCADA PELO METRO DO DISTRITO FEDERAL (ÁGUAS CLARAS)}

Relatório final de pesquisa de Iniciação Científica apresentado à Assessoria de Pós-Graduação e Pesquisa pela Faculdade de Ciências e Tecnologia FACTES

Orientação: Sérgio Garavelli.

\section{MATHEUS YUSEF ALI \\ BÁRBARA S BARBALHO}

BRASÍLIA - 2017

PIBIC 


\title{
AVALIAÇÃO DA CONTAMINAÇÃO ACÚSTICA PROVOCADA PELO METRO DO DISTRITO FEDERAL (ÁGUAS CLARAS)
}

\author{
Bárbara S Barbalho - UniCEUB, PIC Institucional, aluno bolsista \\ barbara_barbalho@hotmail.com
}

Matheus Yusef Ali - UniCEUB, PIC institucional, aluno voluntário
yusef.matheus@me.com

Sérgio Garavelli - UniCEUB, professor orientador

sergio.garavelli@gmail.com

\author{
Armando de Mendonça Maroja - Universidade de Brasília, colaborador \\ amaroja@gmail.com
}

\section{Resumo:}

Nos grandes centros urbanos a demanda por transporte tem aumentado nas últimas décadas, o que gera como consequência o incremento da poluição ambiental. Nas principais cidades brasileiras a principal fonte geradora de poluição sonora é o tráfego rodoviário, porém, em muitas cidades, transporte ferroviário, particularmente o metrô e os veículos leves sobre trilhos (VLT), contribuem para o agravamento deste quadro. Em Brasília, além do ruído emitido pelo tráfego veicular, outra fonte de ruídos devido é o metrô, que em grande parte de seu percurso é de superfície. O Metrô-DF, que é o principal meio de transporte público da cidade, possui uma malha de $42 \mathrm{~km}$, que liga a região administrativa de Brasília às de Ceilândia e Samambaia e seus trilhos atravessam a cidade de um extremo ao outro, transportando em média 140 mil passageiros por dia. Como característica especial, a maior parte da malha metroviária é de superfície, o ruído emitido pela operação atinge a população residente na vizinhança da via, incluindo a cidade de Águas Claras, escolhida para o presenta estudo. Com população de aproximadamente 150 mil habitantes sofrem com problemas ambientais comuns a grandes centros urbanos, como a contaminação acústica. A cidade possui uma longa malha ferroviária de superfície, assim, a operação do metrô gera ruídos que atinge a população residente na vizinhança da via. Este trabalho teve como principal objetivo avaliar os impactos provocados pelo ruído emitido pela operação do metrô, na população de Águas Claras. Para tanto, foram realizadas medições acústicas nas áreas lindeiras à via e elaboradas cartas acústicas referentes aos ruídos gerados pela operação do Metrô. Na elaboração dos mapas de ruídos foram levadas em conta as curvas de níveis de toda a cidade. Os parâmetros acústicos utilizados, Leq(A), L90, L10, Lmin e Lmax foram definidos a partir do nível de pressão sonora equivalente Leq(A): nível do ruído contínuo equivalente ao som produzido durante um dado período de tempo medido com o filtro de frequências na ponderação A. As medidas foram realizadas em áreas residenciais próximas a malha viária. Como resultados, obteve-se níveis de pressão sonora que ultrapassaram $70 \mathrm{~dB}(\mathrm{~A})$ próximo à fachada dos edifícios residenciais, valores que estão acima do limite estabelecido pela legislação brasileira e tem potencial de impacto negativo na qualidade de vida da população. Nas regiões onde a malha metroviária é de superfície, foi constatado que os níveis de pressão sonora produzidos pela passagem do metrô, apesar de intermitente, estão acima do ruído residual, assim como, do limite estabelecido pela legislação distrital. Em função do ruído intermite emitido pela operação do metrô, parâmetros de longo prazo 
como o Lden, que são usados pela legislação vigente para calcular o impacto que gerado na população, não representam de forma fidedigna as alterações na paisagem sonora na vizinhança da malha ferroviária de superfície do metrô. Como resultados também estimado o número de pessoas expostas por faixas do indicador acústico Lden e também a população incomodada e altamente incomodada pelo ruído gerado pelo Metrô.

Palavras chaves: Acústica Ambiental, Mapas de Ruído, Ruído Metrô. 


\section{Lista de Figuras}

Figura 1 - Rede planejada para o programa Circula Brasília........................................................................... 8

Figura 2 - Localização dos locais de medições externas ............................................................................13

Figura 3 - Mapa do ruído emitido pela operação do metrô DF-Ldia ......................................................14

Figura 4 - Mapa do ruído emitido pela operação do metrô DF-Lpico.......................................................15

Figura 5 - Sonômetro Solo da 01 dB, utilizado nas medições. ………………………………………….....22

Figura 6 - Registro de um local de medição............................................................................................22

Figura 7 - Registro de um local de medição............................................................................................21

Figura 8 - Registro da gravação do áudio ..........................................................................................21

Figura 9 - Registro de um local de medição..............................................................................................22

\section{Lista de Tabelas}

Tabela 1 - Níveis de pressão sonora medidos na área residencial, em $\mathrm{dB}(\mathrm{A})$............................................12

Tabela 2 - Níveis de pressão sonora medidos interno, em dB(A).............................................................12

Tabela 3 - População exposta, por faixa do indicador Lpico e percentual de pessoas incomodadas ...15

Tabela 4 - Coordenadas geográficas das medições ....................................................................................19 


\section{Sumário}

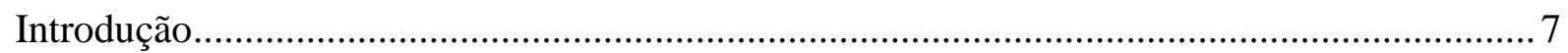

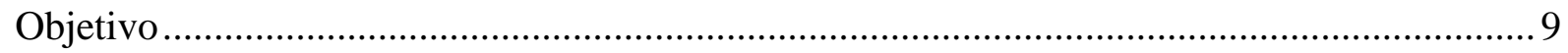

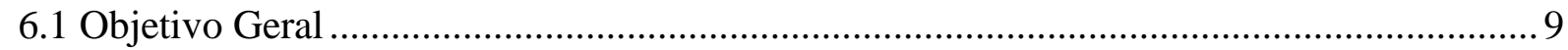

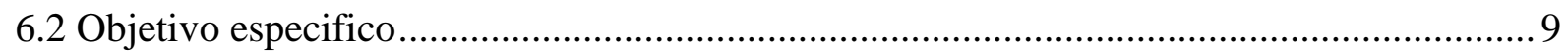

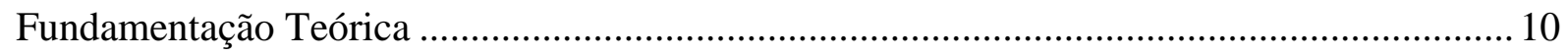

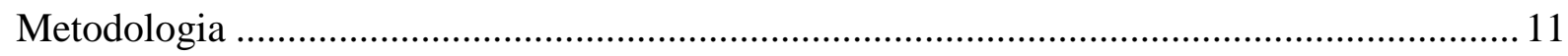

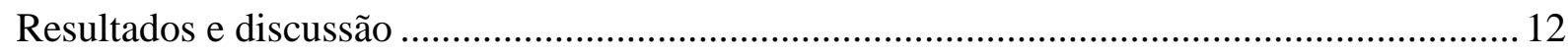

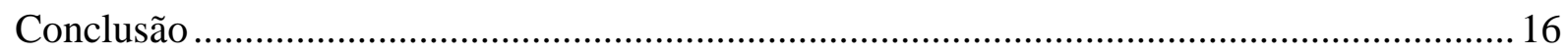

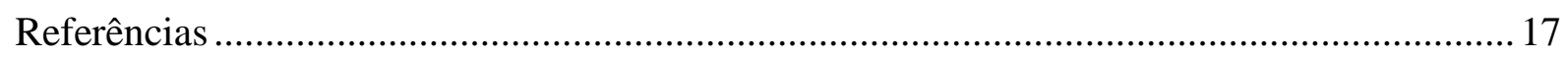

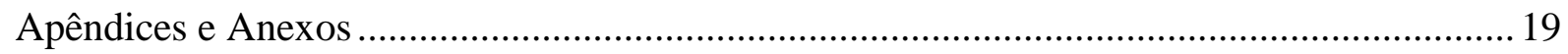




\section{Introdução}

O ruído ambiental, também conhecido como poluição sonora, é considerado um problema de saúde pública. Podendo também ser definido como um som sem harmonia e que geralmente provoca efeitos não desejáveis alterando negativamente a qualidade de vida, causando impactos à saúde (BISTAFA, 2011), em especial no período noturno (WHO, 2009). Freia et al. (2014). Seus efeitos adversos sobre a saúde humana podem ser tanto não auditivos, como distúrbios do sono, zumbido, comprometimento cognitivo em crianças e doenças cardiovasculares, quanto auditivos, como a Perda Auditiva Induzida por Ruído (WHO, 2011).

Enquanto o ruído nos grandes centros urbanos, locais de tráfego intenso, seja ele rodoviário ferroviário ou aéreo, é um dos principais motivos de queixas (WORLD HEALTH ORGANIZATION - WHO, 2011) a demanda por transporte tem aumentado nas últimas décadas.

Os residentes das margens de ferrovias e estradas estão expostos a níveis de pressão sonora (NPS) cada vez mais elevada (GARAVELLI et al., 2014, PAUNOVIĆ et al., 2014). No Brasil o sistema de transporte ferroviário, particularmente o metrô e os veículos leves sobre trilhos (VLT), agregam para a piora do incômodo em relação ao tráfego rodoviário.

No Distrito Federal a taxa média de crescimento da frota de veículos é de aproximadamente $8 \%$ ao ano, em contrapartida o fluxo veicular é a principal fonte móvel de ruído ambiental e devido a isso este contaminante tende a aumentar (GARAVELLI et al., 2014). Além do ruído emitido pelo tráfego veicular outra fonte de ruídos devido ao transporte presente em Brasília é o metrô, que em grande parte de seu percurso é de superfície.

O Distrito Federal, nos anos 90, teve crescimento populacional causada pela migração brasileira para os grandes centros urbanos, surgindo assim novas Regiões Administrativas. Comprometeu assim alguns setores, como por exemplo o sistema de transporte. As longas distâncias entre as Regiões Administrativas e Brasília e a saturação dos principais corredores rodoviários, são fatores que foram determinantes para a construção do metrô.

0 Metrô-DF liga Brasília às regiões administrativas de Ceilândia e Samambaia e conta com uma malha de $42 \mathrm{~km}$, figura 1 . Tem frota de 32 trens, com duas séries, 20 trens são da série 1000 (mais antigos) e 12 trens são da série 2000 (mais novos). Transportando em média 160 mil passageiros por dia. A maior parte da malha metroviária é de superfície, ou seja, em trincheiras, a céu aberto, sobre aterros ou em faixas isoladas do terreno. Com esta característica o ruído ambiental emitido pelo seu funcionamento atinge a população residente na vizinhança da malha de superfície, mas propiciou um menor custo da construção do sistema. Os usuários nas estações e no interior dos vagões, durante o trajeto, também estão expostos aos ruídos emitidos pela operação do metrô.

O Metrô-DF trabalha com duas linhas em formato "Y". A linha começam na estação Central, situada no subsolo da Rodoviária do Plano Piloto, e trafegam conjuntamente até a estação Águas Claras, onde é separada em dois ramais, veja destaque na Figura 1. Os trens têm uma alimentação elétrica que é realizada por um terceiro trilho e deslocam-se com uma velocidade máxima de até $80 \mathrm{~km} / \mathrm{h}$. 


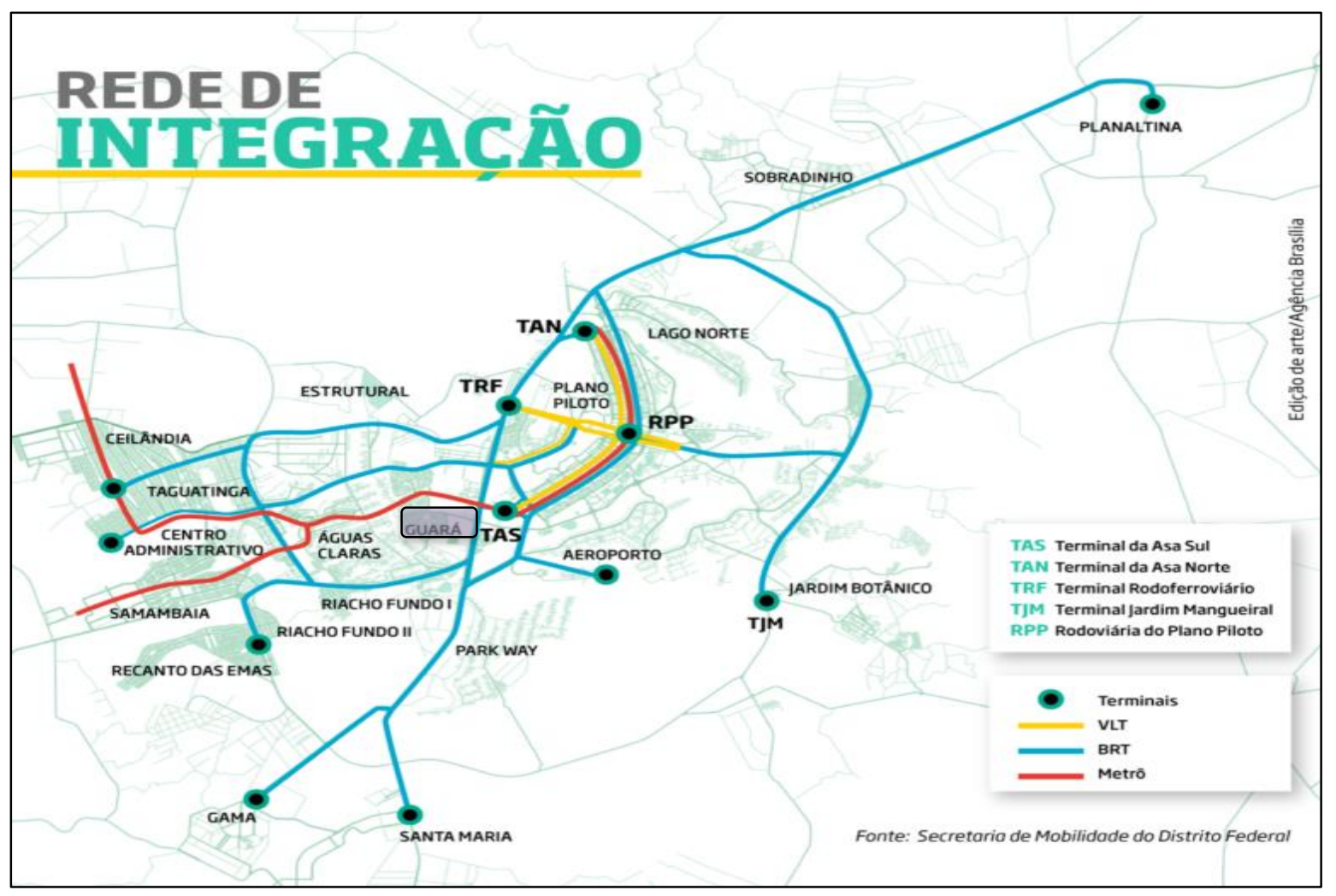

Figura 1 - Rede planejada para o programa Circula Brasília.

Fonte: Secretaria de Mobilidade do DF 


\section{Objetivo}

\subsection{Objetivo Geral}

Ao analisarmos o incomodo da população que reside próximos à malha ferroviária da cidade de Águas Claras. Visamos avaliar o impacto relativo á operação do metrô, e calcular a faixa da população exposta ao ruído. Este trabalho é consequência de um estudo anterior (GARAVELLI et al., 2016) que avaliou os níveis de pressão sonora nas comunidades, estações e no interior das composições no Metrô do Distrito Federal.

\subsection{Objetivos específicos}

- Realizar medidas acústicas.

- Monta banco de dados para a elaboração dos mapas de ruídos.

- Elaborar mapas de ruídos devido a operação do Metrô-DF.

- Determinar o número de pessoas expostas por faixa do indicador Lden e Ln.

- Determinar o número de pessoas incomodadas e altamente incomodadas pelo ruído gerado pela operação do metrô.

- Determinar o número de pessoas com distúrbios no sono em função da exposição do ruído gerado pela operação do metrô.

- Comparar os NPS gerados pela operação do metro, que atinge as áreas habitadas os limites estabelecidos pela legislação (Distrito Federal, 4092, 2008). 


\section{Fundamentação Teórica}

Estudos envolvendo acústica ambiental visando avaliar o ruído ambiental devido ao metrô mostram NPS superiores aos limites legais (MOHANAN et al., 1989; QUERCUS, 2014). Mesmo nas plataformas subterrâneas e no interior de vagões os NPS são elevados (LANG E STANI, 1977; SOETA e SHIMOKURA, 2012). Gershon et al. (2006) avaliaram o ruído ambiental nas plataformas e no interior dos vagões do metrô de Nova York. Nas plataformas subterrâneas encontram a média de $86 \mathrm{~dB}(\mathrm{~A})$, com valores máximos acima de $112 \mathrm{~dB}(\mathrm{~A})$, que excedem em mais de $30 \mathrm{~dB}$ os limites de exposição recomendados da Organização Mundial de Saúde (OMS).

Pesquisas relacionadas com a emissão de ruídos por veículos leves sobre trilhos indicam que as versões mais recentes são menos ruidosas, afetando com menor magnitude a paisagem sonora das regiões vizinhas às vias. (ALSTOM, 2012; MAROJA et al., 2013 e 2014).

González e Calle (2014) desenvolveram uma pesquisa na cidade de Bogotá, Colômbia, com medidas acústicas e avaliação da percepção da população em relação aos ruídos emitidos por veículos, além de observarem níveis de pressão sonora elevados, o que provoca danos a qualidade de vida e à saúde da população, identificaram a incidência de fatores não acústicos em relação aos incômodos percebidos pela população. Okokon et. al. (2015) concluíram que uma proporção considerável de adultos finlandeses são altamente irritado com ruído do tráfego rodoviário, e consideram como um risco significativo à saúde, e a qualidade de vida.

Gershon et al. (2006) avaliaram nos NPS nas plataformas e no interior dos vagões do metrô de Nova York. Nas plataformas subterrâneas encontram a média de $86 \mathrm{~dB}(\mathrm{~A})$, com valores máximos acima de $112 \mathrm{~dB}(\mathrm{~A})$. Os resultados indicaram que nas plataformas de embarque/desembarque do metro os NPS excedem os 7 limites exceder as diretrizes de exposição recomendados da Organização Mundial de Saúde (OMS) e da Agência de Proteção Ambiental dos EUA (EPA), dada a duração da exposição suficiente. Os autores indicam que estratégias de redução de risco devem ser aplicadas, para reduzir a exposição ao ruído de metrô.

Singal et al. (1989) avaliaram os NPS no metrô de Calcutá, Índia, os resultados do indicaram que os níveis de ruído e vibração são mais elevados do que os limites recomendados para conforto. Foram analisados os principais fatores responsáveis por excesso de ruídos e medidas mitigadores para a redução dos NPS foram sugeridas.

Em Portugal, um estudo realizado pela associação ambientalista Quercus (2014) indica que os passageiros do Metropolitano de Lisboa estão sujeitos a níveis de ruído superiores aos limites legais e que, conjugados com o ruído ambiente, podem representar riscos para a saúde. Este estudo surge um dia depois de a Câmara de Lisboa ter aprovado o seu Plano de Ação do Ruído, com medidas para minimizar este problema nas ruas da capital. As medições, realizadas registaram em todos os percursos um nível médio de ruído superior a $80 \mathrm{~dB}(\mathrm{~A})$. 


\section{Metodologia}

Para a realização desse estudo foram feitas medições acústicas e elaborados os mapas dos ruídos relativos à operação do metrô na região da cidade de Águas Claras, mostrada em destaque na Figura 1. Para analisar o ruído ambiental os parâmetros acústicos foram definidos pelo nível de pressão sonora equivalente Leq(A): nível do ruído contínuo equivalente ao som produzido durante um dado período de tempo medido com o filtro de frequências na ponderação A. Foram avaliados os seguintes parâmetros: nível equivalente de pressão sonora Leq(A) e Lpico. As medidas foram realizadas em áreas residenciais próximas a malha viária do metrô.

O equipamento utilizado para as medições foi o sonômetro Solo da $01 \mathrm{~dB}$, com tripé, o tempo medido foi de 15 minutos em cada locação e o período das medições foi de novembro de 2016 a julho de 2017. O sonômetro Solo da $01 \mathrm{~dB}$ tem como principais características e funções: metrologia de precisão; cumpre com a norma IEC 61672; análise da frequência em tempo de oitava; medições paralelas de todos os indicadores; calibração em laboratório acreditado INMETRO (RBC, CHROMPACK), foi utilizado o calibrador Acústico da $01 \mathrm{~dB}$ Steel.

A análise foi realizada com uso do software dBTraid da $01 \mathrm{~dB}$, o equipamento foi calibrado antes e após a realização das medidas. Para efeitos de comparação entre os parâmetros obtidos e os limites da Legislação foi considerada a NBR 10.151 - Avaliação do ruído em áreas habitadas, visando o conforto da comunidade (Rio de Janeiro: ABNT, 2000). Para cada medida foi feita a análise em bandas $1 / 3$ de oitavas, que permitiu a verificação da existência de componentes tonais.

Para a elaboração dos mapas acústicos foi utilizado o software SOUNDPLAN, no qual foram inseridos: a cartografia base, a altimetria do terreno e as curvas de nível. Como fonte de ruído foi considerado apenas o ruído do tráfego ferroviário devido aos trens do metrô. Para a modelagem do ruído foi utilizado o modelo de propagação RMR-2002-Categoria 7. O passo da malha foi estabelecido em $5 \mathrm{~m}$ para os mapas de ruído com altura de cálculo de $4 \mathrm{~m}$. Para os mapas de corte transversal malha foi de $1 \mathrm{~m}$ e a altura de cálculo de $40 \mathrm{~m}$.

Em seguida, a realização dos mapas acústicos, calculamos a população exposta, pois as curvas de ruído, geradas pelo SoundPlan, serão sobreposta com a camada de base censitária. Avaliado o número de edifícios consequentemente o número de residências, utilizamos a base média de habitantes por domicílio, 2,83 (PDAD/DF 2016). Assim estimouse o número de pessoas expostas por faixa do indicador Ldn. 


\section{Resultados e discussão}

$\mathrm{Na}$ Tabela 1 estão apresentados os resultados das medidas realizadas em áreas residenciais da região administrativa de Águas Claras. Os locais foram escolhidos em função de estarem localizados próximos à malha viária de superfície do metrô e distantes de regiões com grande fluxo de veículos e fontes fixas de ruído.

De acordo com a legislação atual do DF, a Lei 4.092 de 2008, Leq, não deve ultrapassar $50 \mathrm{~dB}(\mathrm{~A})$ para o período diurno, e $45 \mathrm{~dB}(\mathrm{~A})$ para o noturno, em áreas residenciais. Porém de acordo com os resultados, os NPS medidos no período diurno variaram de 58,2 a $78,2 \mathrm{~dB}(\mathrm{~A})$, valores acima do limite estabelecido pela Lei. Conforme foi constatado, o ruído ambiental tem como fonte ruído gerado pela operação do metrô, que denominamos de ruído principal e também ao som residual do ambiente, cuja fonte principal é o tráfego veicular, mas levam em conta os outros ruídos no ambiente.

Tabela 1 - Níveis de pressão sonora medidos na área residencial, em dB(A)

\begin{tabular}{cccccccc}
\hline Índice & Trem 1 & Trem 2 & Trem 3 & Trem 4 & Trem 5 & Trem 6 & Lmédio \\
\hline Medição 1 & 64,1 & 65,2 & 71,6 & 66,5 & & & 67,9 \\
Medição 2 & 58,2 & 72,8 & 71,3 & 67,6 & 68,5 & & 69,6 \\
Medição 3 & 70,1 & 66,2 & 72,6 & 78,2 & 75,2 & & 74,2 \\
Medição 4 & 72,9 & 69,2 & 68,8 & 66,9 & 64,4 & 67,0 & 69,4 \\
Medição 5 & 65,5 & 73,6 & 69,3 & 76,3 & 71,3 & & 71,8 \\
\hline
\end{tabular}

Com o objetivo de identificar com mais precisão a contribuição de cada fonte para o ruído ambiental total, foram analisados os espectros sonoros das medidas separando o som residual do ruído principal, ou seja, espectro sonoro da passagem do metro foi recortado do espectro medido e então foi determinado o ruído principal para cada medida. Os resultados estão apresentados na Tabela 1.

Além das medições nas áreas externas, aferimos os níveis de pressão no interior de uma residência, localizada, no segundo andar de um edifício próximo malha ferroviária, os resultados estão apresentados na Tabela 2.

Tabela 2 - Níveis de pressão sonora medidos interno, em dB(A).

\begin{tabular}{cccccc}
\hline Residencial Araucárias & Trem 1 & Trem 2 & Trem 3 & Trem 4 & Lmédio \\
\hline 1 & 71,3 & 68,9 & 73,9 & 71,7 & 72,1 \\
\hline
\end{tabular}

A localização dos pontos de medida, indicados na Figura 2, em relação ao nível dos trilhos do metrô foi escolhida de forma a contemplar todos os cenários presentes na área de estudo. Em alguns pontos os trilhos encontram-se próximos da superfície da rua, em outros em uma trincheira com vários metros de profundidade e ainda em posições elevadas de alguns metros acima da superfície em aterros. A posição dos pontos de medida em relação à linha e a distância desses pontos ao eixo da linha explicam as variações encontradas. 


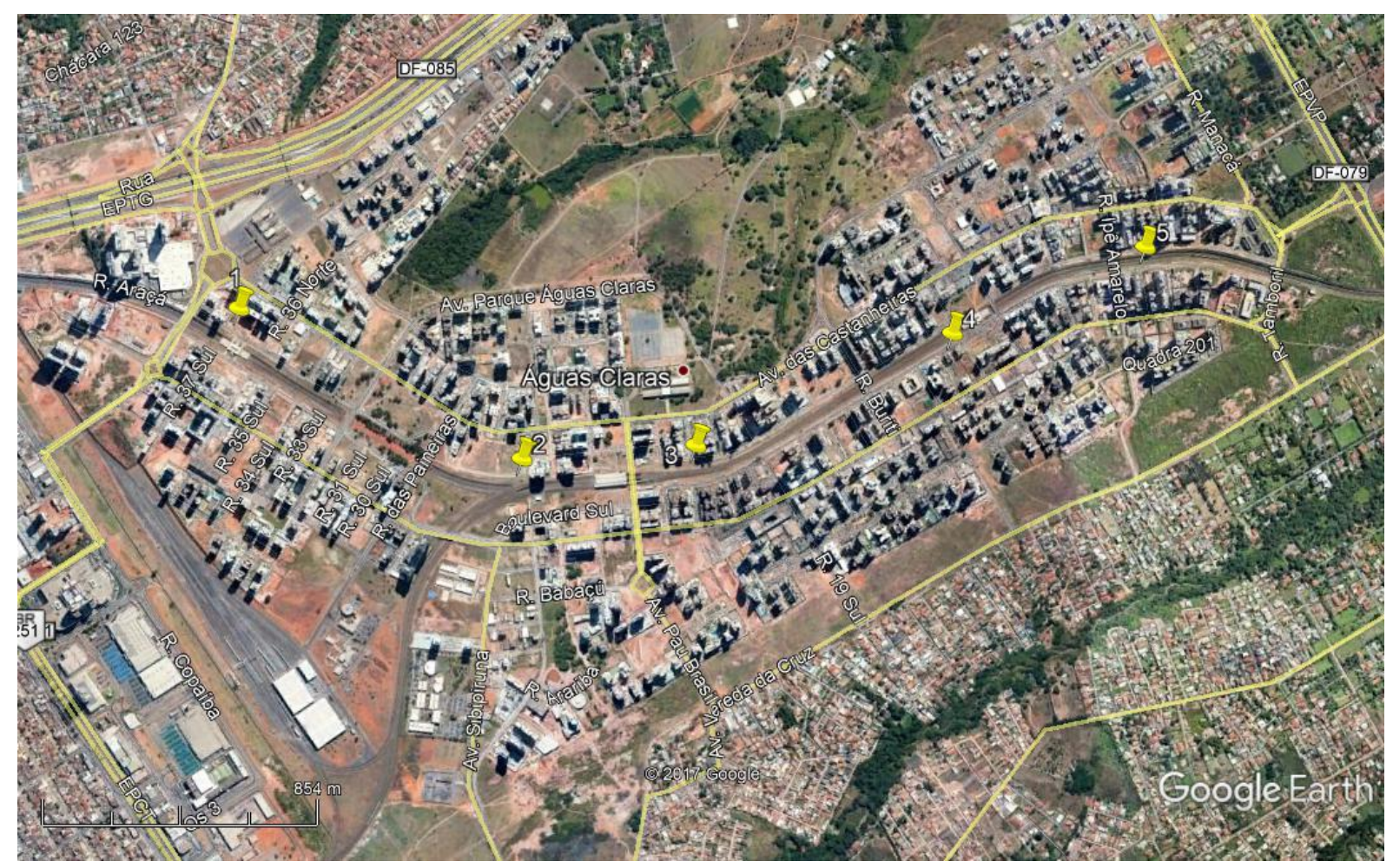

Figura 2 - Localização dos locais de medições externas

Fonte: Elaboração própria

A Figura 3 apresenta o mapa de ruídos correspondente a operação do metrô. O parâmetro utilizado na elaboração do mapa foi Ldia, que consideramos como o Leq calculado no período de operação do metrô (6h-23h horas), levando em consideração a frequência de passagem dos trens durante cada período do dia, num total de 213 passagens (METRO DF, 2017). Na região onde o metrô é de superfície não há barreiras acústicas implantadas próximas a linha férrea. 


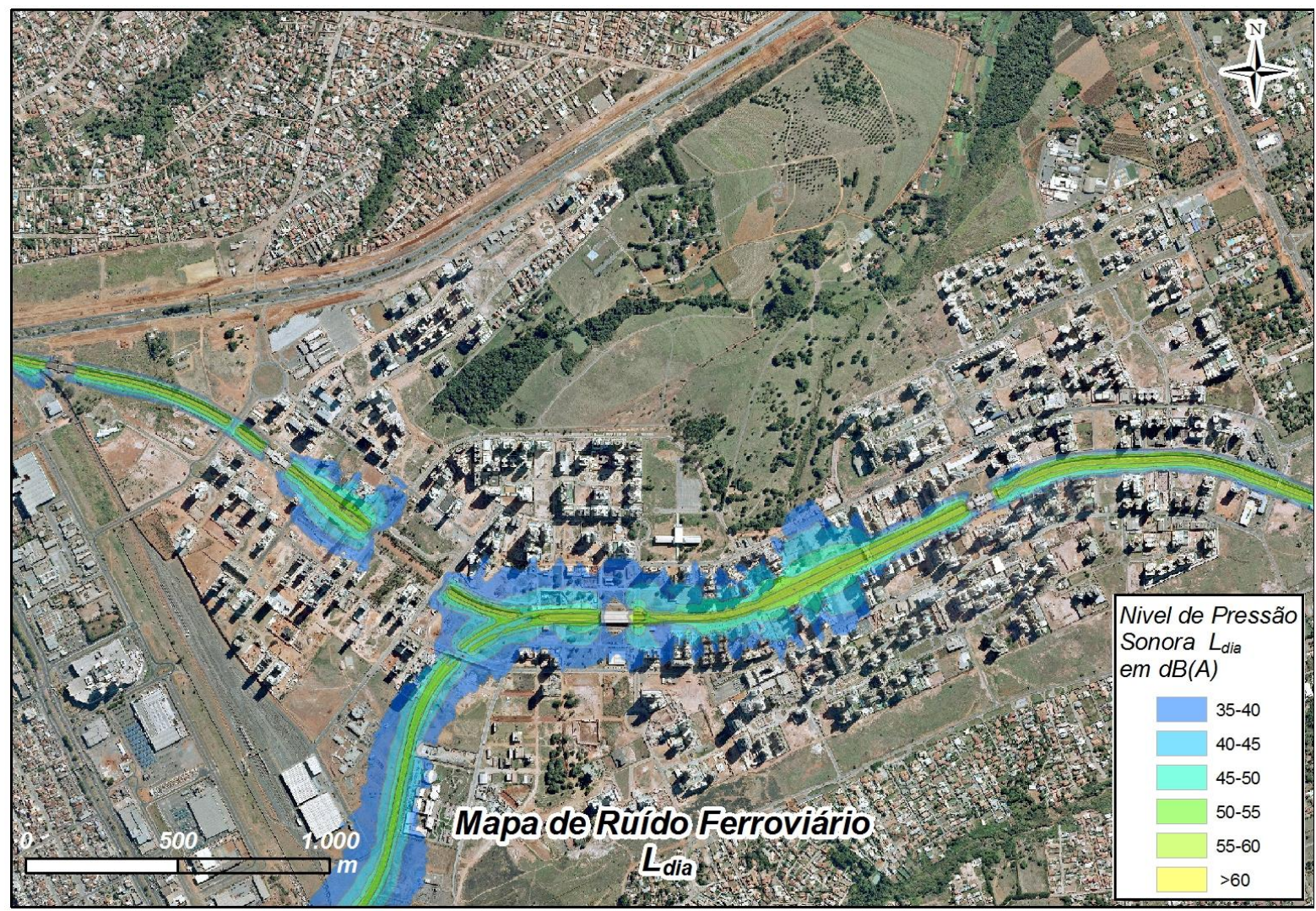

Figura 3 - Mapa do ruído emitido pela operação do metrô DF-Ldia

Fonte: Elaboração própria

A Figura 4 podemos observar o mapa de ruídos correspondente a operação do metrô no momento do pico. O parâmetro utilizado nesse caso foi o momento de maior intensidade de ruído no período de trafego do trem. Na região onde o metrô é de superfície não há barreiras acústicas implantadas próximas a linha férrea.

A partir dos mapas foram calculadas o número de residências e o número de pessoas expostas por faixa do indicador de ruído Lpico. A estimativa do número de pessoas incomodadas e altamente incomodadas pelo ruído emitido pelo metrô foi feita utilizando as Miedema e Vos (1998), apresentadas a seguir. Na equação \%I, representa o percentual de pessoas incomodadas e \%AI altamente incomodadas. Os resultados estão apresentados na Tabela 3.

$$
\begin{aligned}
& \% I=4,552 \times 10^{-4}(N P S-37)^{3}+9,400 \times 10^{-3}(N P S-37)^{2}-0,212(N P S-37) \\
& \% A I=7,158 \times 10^{-4}(N P S-42)^{3}-7,774 \times 10^{-3}(N P S-42)^{2}+0,163(N P S-42)
\end{aligned}
$$




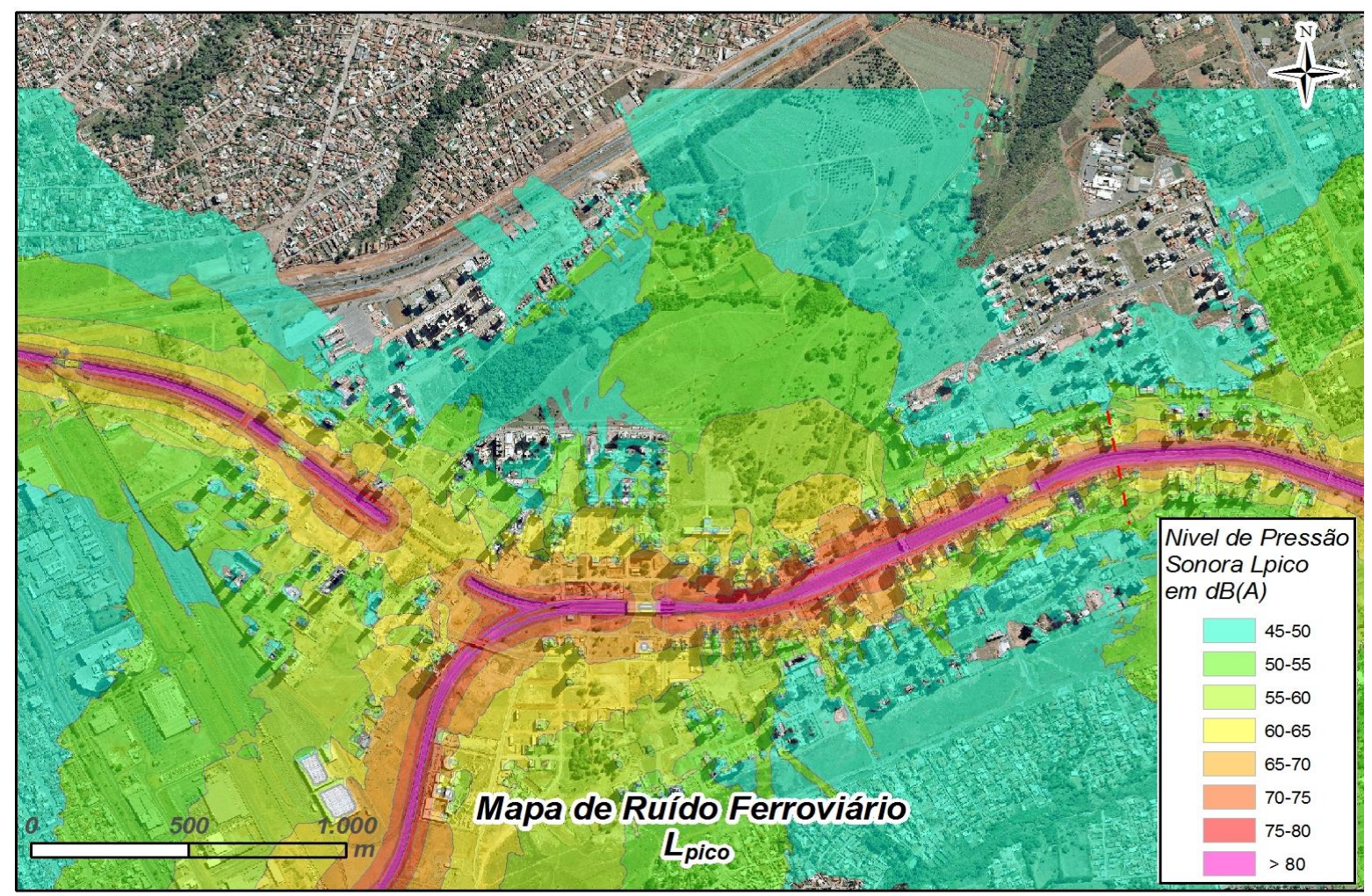

Figura 4 - Mapa do ruído emitido pela operação do metrô DF-Lpico.

Fonte: Elaboração própria.

Tabela 3 - População exposta, por faixa do indicador Lpico e percentual de pessoas incomodadas

\begin{tabular}{cccccc}
\hline Lpico $\mathrm{dB}(\mathrm{A})$ & Área $\left(\mathrm{km}^{2}\right)$ & Residências & Habitantes & $\% \mathrm{I}$ & NPI \\
\hline $50-55$ & 1,19 & 4439 & 12562 & 0,0067 & 84 \\
$55-60$ & 0,65 & 3189 & 9025 & 0,0353 & 318 \\
$60-65$ & 0,41 & 1775 & 5023 & 0,0825 & 415 \\
$65-70$ & 0,21 & 1056 & 2988 & 0,1519 & 454 \\
$70-75$ & 0,14 & 145 & 410 & 0,2469 & 101 \\
$>75$ & 0,15 & 6 & 17 & 0,4446 & 8 \\
\hline
\end{tabular}

Os resultados indicam o total de 1380 pessoas incomodadas (NPI) pelo ruído do tráfego do metrô, em Águas Claras, sendo que o número altamente incomodadas foi desprezível. A organização mundial da saúde, possui estudos que relata que as exposições a ruídos ambientais não atingem somente o sistema auditivo humano, assim como podem causar, estresse, incômodo no sono, mas o distúrbio no sono não é considerado devido que a operação do metrô é de 6:00 as 23:00 horas ocasionando perda na qualidade de vida desta população. 


\section{Conclusão}

Como as avaliações foram realizadas no período diurno, quando os NPS devido ao som residual são maiores, assim como o limite da legislação, pode-se concluir que no período noturno os níveis de pressão sonora gerados pela operação do metrô nas vizinhanças da malha metroviária de superfície terão um maior impacto na população residente nestes locais.

Nas regiões onde a malha metroviária é de superfície, foi constatado que os níveis de pressão sonora produzidos pela passagem do metrô, apesar de intermitente, estão acima do ruído residual, e também acima do limite estabelecido pela legislação distrital. Esses níveis têm potencial de causar impactos negativos na população ali residente.

Os resultados do trabalho indicam que em função do ruído intermite emitido pela operação do metrô, parâmetros de longo prazo como o Lden, por exemplo, não representam de forma fidedigna as alterações na paisagem sonora na vizinhança da malha ferroviária de superfície do metrô.

As desconformidades observadas em relação à legislação vigente indicam que a operação do Metrô-DF tem potencial de provocar incômodo à população residente próxima a via de superfície e aos usuários, o que sugere um estudo para avaliar a percepção da população em relação a estes ruídos.

Observação: Parte deste trabalho foi apresentado na XVIII - Reunião da SOBRAC, Sociedade Brasileira de Acústica, na forma de trabalho oral, o trabalho apresentado segue em anexo. 


\section{Referências bibliográficas}

AGÊNCIA BRASÍLIA. Capital terá 277 km de rede integrada de transporte público. 2016. Disponível em: <http://www.agenciabrasilia.df.gov.br/2016/05/24/capital-tera-277-km-de-rede-integrada-de-transportepublico/>. Acesso em: 08/02/2016.

ALSTOM. Generating sustainable mobility. Disponível em: <http://www.cleanmobility.alstom.com /upload/ alstom_en.pdf>. Acesso em: 25/06/2012.

FREIA, P.; MOHLERA E.; RÖÖSLIA, M. Effect of nocturnal road traffic noise exposure and annoyance on objective and subjective sleep quality. International Journal of Hygiene and Environmental Health, 217(23), p. 188-195, 2014.

GARAVELLI S. L. et al. A contaminação acústica provocada pelo Metrô do DF. In: $7^{\circ}$ Congresso LusoBrasileiro para o Planejamento Urbano, Regional Integrado e Sustentável, Maceió-Brasil, 2016.

GARAVELli, S. L.; MAROJA, A. M.; COSTA, C. A; CARVALHO Jr, E. B. O Projeto de Lucio Costa para Brasília DF e a Contaminação Acústica. In: $6^{\circ}$ Congresso Luso-Brasileiro para o Planejamento Urbano, Regional Integrado e Sustentável, 2014, Lisboa-Portugal, 2014.

GERSHON, R. R. M.; NEITZEL, R.; BARRERA M. A.; AKRAM M. Pilot Survey of Subway and Bus Stop Noise Levels. Journal of Urban Health: Bulletin of the New York Academy of Medicine, 83(5), p. 802-812, 2006.

LANG, J.; STANI, M. Measures against noise in Subway stations. Journal of Sound and Vibration 51(3), p. 365-367, 1977.

MIEDEMA, H.M.E e Vos, H. (1998). Exposure-response relationships for transportation noise. Journal of the Acoustical Society of America. v. 104, n. 6, p. 3432 - 3445.

MAROJA, A. M.; SANTOS, F. S.; CARVALHO JR., E. B.; GARAVELLI, S. L. Análise Espacial do Impacto Ambiental Acústico Provocado pela Implantação do VLT em Brasília - DF In: $6^{0}$ Congresso Luso-Brasileiro de Planejamento Urbano, Regional e Integração Sustentável, Lisboa-Portugal, 2014.

MAROJA, A. M.; SANTOS, F. S.; GARAVELLI, S. L.; CARVALHO JR., E. B. Veículo Leve sobre Trilhos: Impacto Ambiental Acústico em Brasília-DF. In: XXVII ANPET-Congresso de Pesquisa e Ensino em Transportes, Belém-PA, 2013.

METRO_DF. Horário de funcionamento. 2017. Disponível em: <http://www.metro.df.gov.br/horario-defuncionamento-2/>. Acesso em: 08/02/2017.

MOHANAN, V.; SHARMA, O.; SINGAL, S. P. Applied Acoustics. A Noise and Vibration Survey in an Underground Railway System 28, p. 263-275, 1989.

PAUNOVIĆ, K.; BELOJEVIĆ, G.; JAKOVLJEVIĆ, B. Noise annoyance is related to the presence of urban public transport. Science of the Total Environment 481, p. 479-487, 2014.

QUERCUS. Metro de Lisboa com níveis de ruído prejudiciais à saúde. 2015. Disponível em: <https://www.publico.pt/local/noticia/metro-de-lisboa-com-niveis-de-ruido-prejudiciais-a-saude-1694080>. Acesso em: 01/02/2016.

SOETA, Y.; SHIMOKURA, R. Sound field characteristics of underground railway stations-Effect of interior materials and noise source positions. Applied Acoustics, 73(11), p. 1150-1158, 2012.

WORLD HEALTH ORGANIZATION. Burden Night Noise Guidelines for Europe. WHO Regional Office 
for Europe, Copenhagen, Denmark, 2009.

WORLD HEALTH ORGANIZATION. Guidelines for Community Noise. World Health Organization, Geneva, 1999. 
Apêndice I - Coordenadas geográficas dos locais de medições

Tabela 4 - Coordenadas geográficas das medições

\begin{tabular}{ccc}
\hline Localização & Latitude & Longitude \\
\hline 1 & $-15,8345$ & $-48,0368$ \\
2 & $-15,8396$ & $-48,0310$ \\
3 & $-15,8398$ & $-48,0259$ \\
4 & $-15,8375$ & $-48,0180$ \\
5 & $-15,8357$ & $-48,0120$ \\
\hline
\end{tabular}




\section{Apêndice II - Registro fotográfico dos locais de medições}

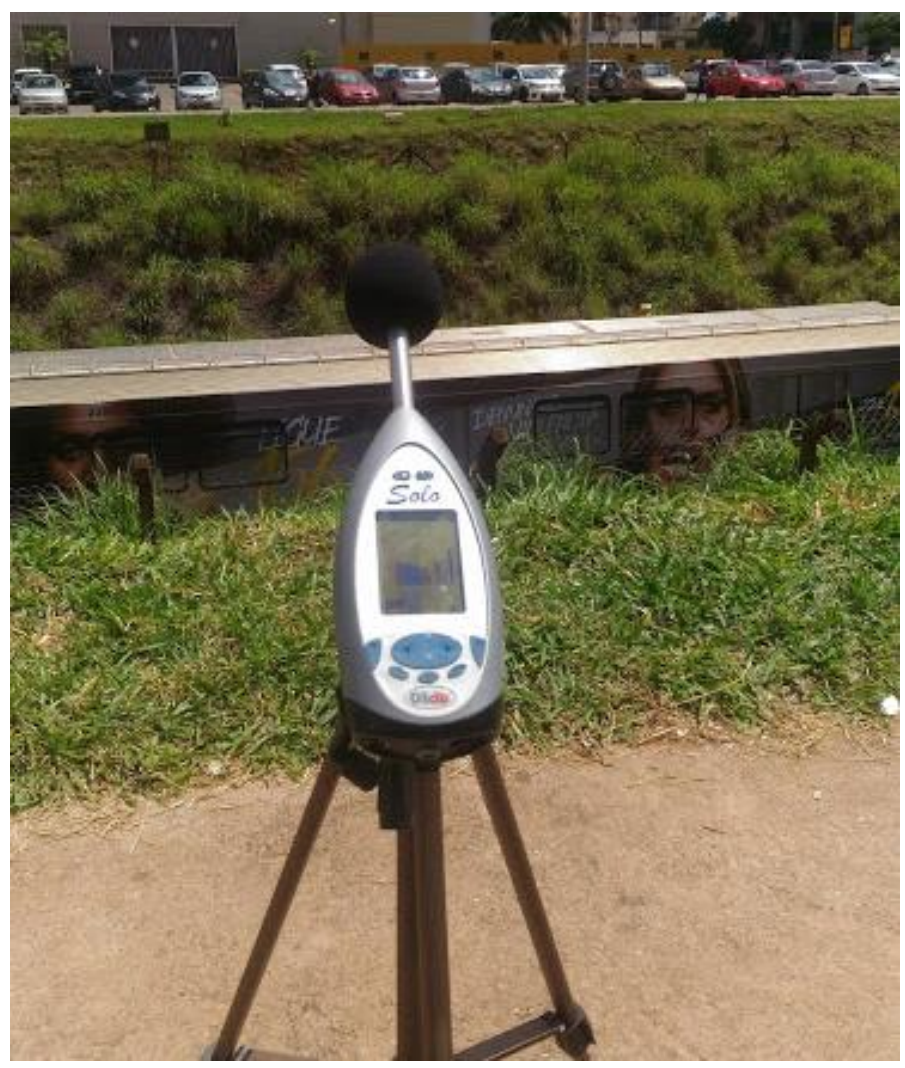

Figura 5 - Sonômetro Solo da $01 \mathrm{~dB}$, utilizado nas medições. Fonte: Elaboração própria.

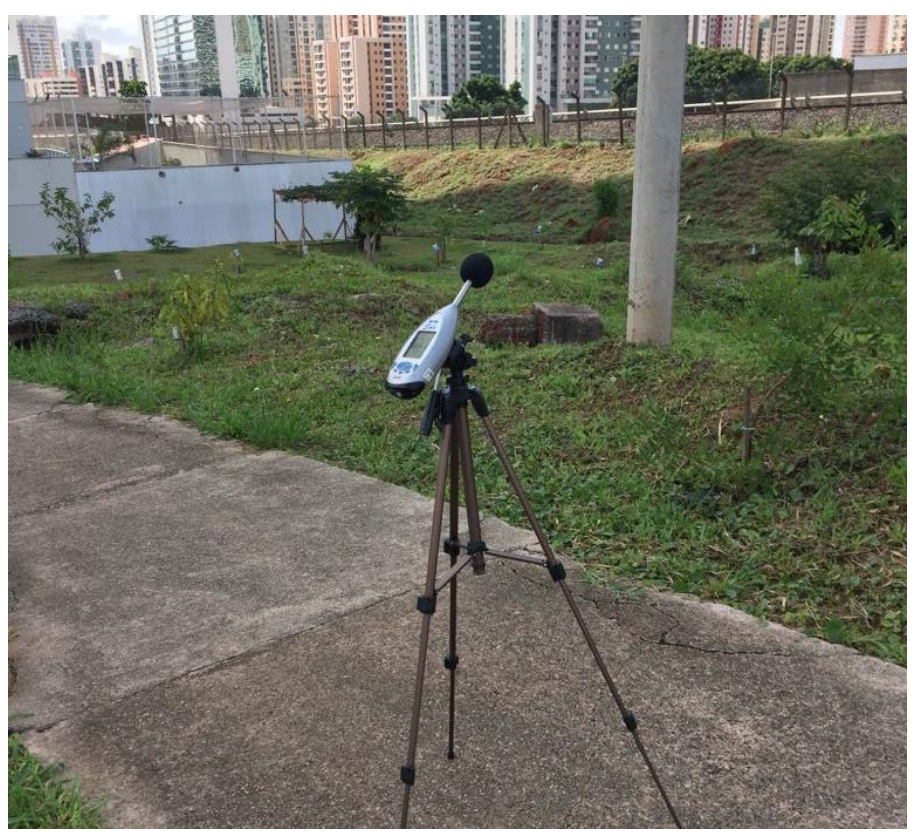

Figura 6 - Registro de um local de medição Fonte: Elaboração própria. 


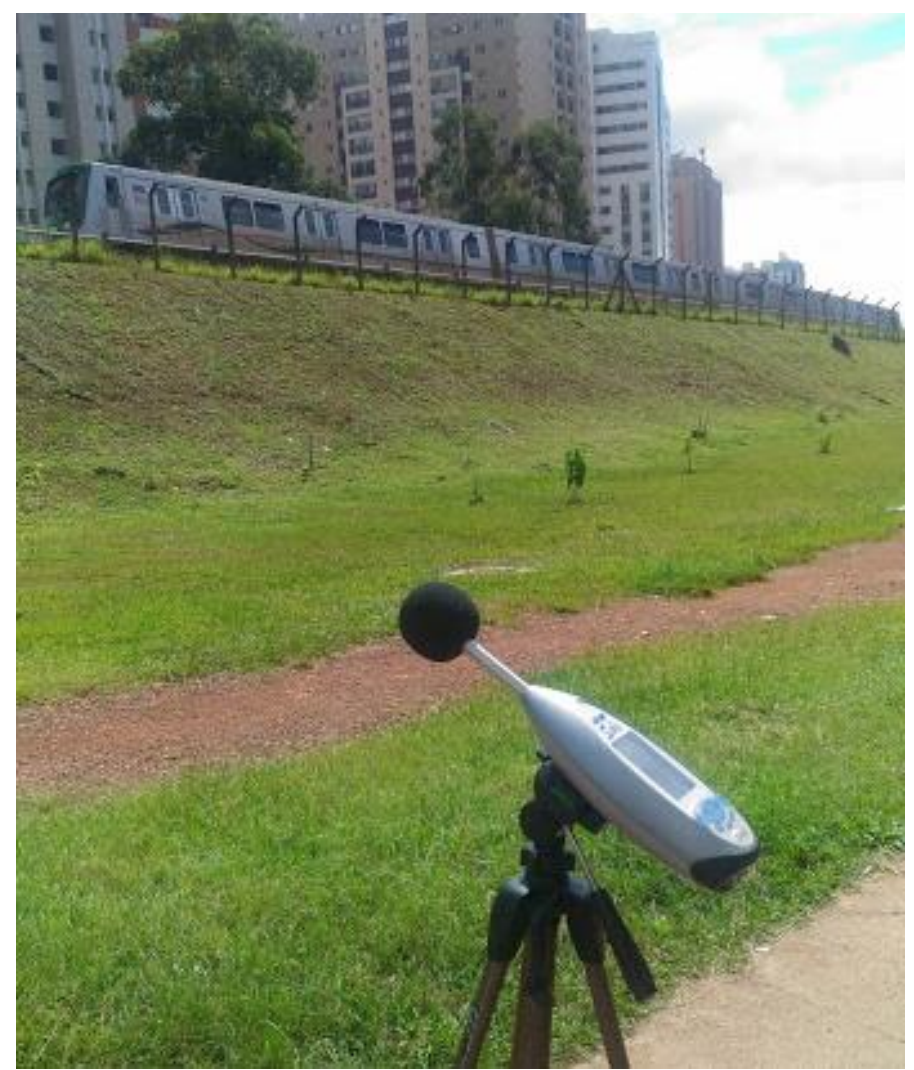

Figura 7 - Registro de um local de medição Fonte: Elaboração própria.

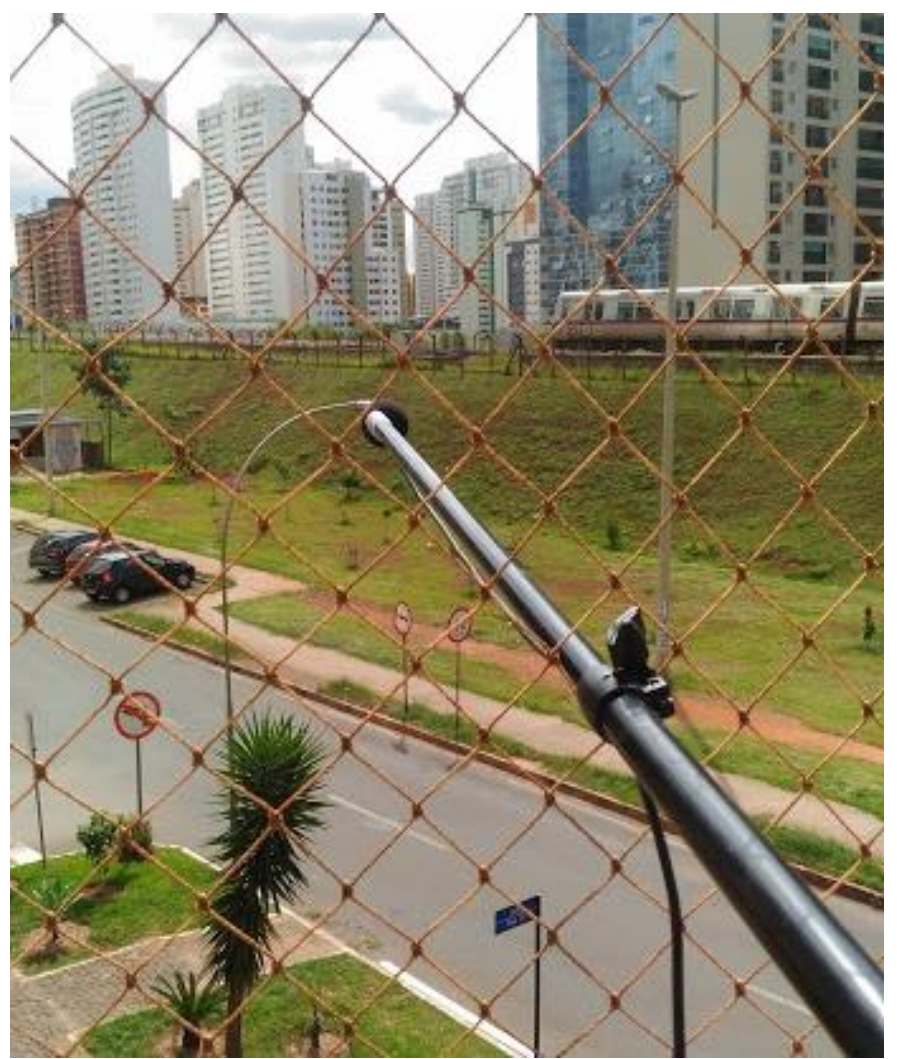

Figura 8 - Registro da gravação do áudio Fonte: Elaboração própria. 


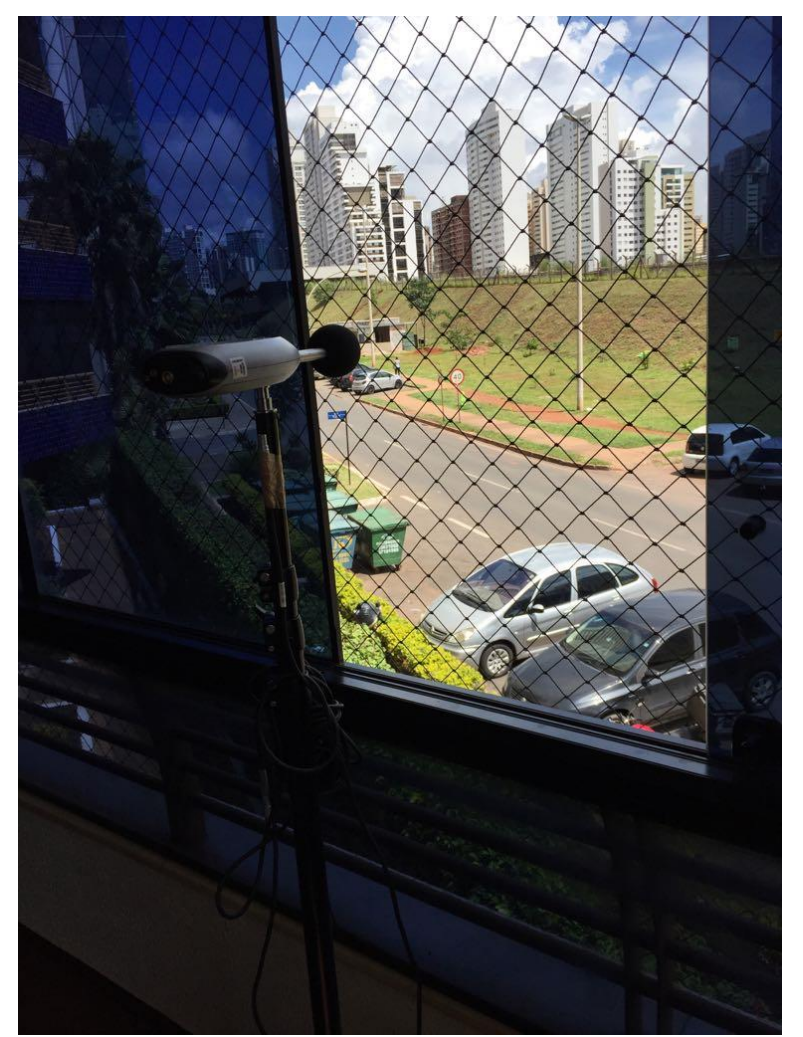

Figura 9 - Registro de um local de medição Fonte: Elaboração própria. 